\title{
Credit usage among the un(der) banked: consumer socio-economic characteristics and influence of financial technology
}

\author{
Davis Bundi Ntwiga \\ School of Mathematics, \\ University of Nairobi, \\ Nairobi, Kenya \\ Email: dbundi@uonbi.ac.ke
}

\begin{abstract}
We use the 2016 FinAccess Household survey data of 2015 from 8665 households to analyse how the socio-economic characteristics and financial literacy of un(der) banked consumers can shape their dynamics towards credit usage. A qualitative analysis is presented on the influence of financial technology on consumer credit usage. The access to financial services is influenced by the socio-economic characteristics and financial literacy of the consumers. Gender, financial literacy, age, income, marital status, education level and geographical cluster are statistically significant in influencing credit usage, both current and past usage relative to never had credit. As financial technology continues to expand and offer credit, there is need to understand the user experience to match their social and economic status as a means to increase credit usage in Kenya.
\end{abstract}

Keywords: credit usage; un(der)banked; consumer; socio-economic; financial technology; financial services.

Reference to this paper should be made as follows: Ntwiga, D.B. (2020) 'Credit usage among the un(der) banked: consumer socio-economic characteristics and influence of financial technology', Int. J. Financial Services Management, Vol. 10, No. 1, pp.38-54.

Biographical notes: Davis Bundi Ntwiga is a Lecturer and research associate in the School of Mathematics, University of Nairobi, Kenya. He has over ten years teaching, research and data analytics experience, having worked in the financial, educational and research institutions; and as a consultant in statistical software, training, data science and analytics. He has a $\mathrm{PhD}$ in Financial Mathematics and has published widely in peer-reviewed journals with research interests in financial inclusion, financial markets, social networks, credit risk and climate change.

This paper is a revised and expanded version of a paper entitled 'Can Fintech shape the dynamics of consumer credit usage among the un(der) banked?' presented at the 'Kenya Bankers Association 7th Banking Research Conference', Nairobi, Kenya, 21 September 2018.

\section{Introduction}

Financial inclusion is critical in reducing poverty and increasing inclusive economic growth, and inclusion increases with lower account costs, in politically stable 
environments, stronger legal rights and the proximity to financial providers (Allen et al., 2016; Demirguc-Kunt et al., 2015). Financial exclusion is either voluntary or involuntary, with the involuntary reasons being due to insufficient income, discrimination, lack of information, price barriers, product features or weak contract enforcement (Amidzic et al., 2014). Globally, around 1.7 billion adults are unbanked, $56 \%$ of the unbanked are women and $50 \%$ of the unbanked come from $40 \%$ of the poorest households, while $73 \%$ of the 1.7 billion reside in 25 countries, mostly in Asia and Africa (IFC, 2017). A comparison of the gender shows that $72 \%$ of the men have an account compared with $65 \%$ of the women, which has remained unchanged since 2011 (Demirguc-Kunt et al., 2017).

Financial institutions are in the forefront to foster financial inclusion. The SubSaharan Africa (SSA) has been among the fastest growing regions in the world since the 1990s and the growth has led to expansion of access to financial services through agent banking and mobile money (Mecagni et al., 2015). The estimated global financial opportunity from the un(der) banked customers is USD 380 billion in annual revenues (IFC, 2018). These are the opportunities for the financial service providers. Innovations in credit market are deliberate to employ business models that are mobile platform based, data intensive and capital light (Demirguc-Kunt et al., 2017). The disruptive technologies will be a continuous event to innovate and shape customer behaviour (McWaters, 2015). The evolution of the digital wallet has created a battle between traditional financial service providers and disruptors. They provide the consumers with fast, low-cost and secure method to use, store and send money (PWC, 2020).

Credit scoring has always been a challenge among the un(der) banked due to lack of financial histories data (Ntwiga, 2016) but Ntwiga et al. (2018) noted that micro-credit lending to peer groups enhances credit risk analysis. Digital credit providers are using different avenues of data to solve this problem. KCB Mpesa and MShwari partnership with Safaricom Kenya use telecommunication variables to score, manage and disburse loans. Equity bank utilises the bank account data and credit reference bureau data to score and allocate credit. Tala and Branch FinTechs have smart phone-based applications to collect phone usage information and Facebook data for the latter to score customers (Totolo, 2018; Hwang and Tellez, 2016). New players are coming to the market every year as their services and products continue to be popular even among the un(der) banked.

FinTech deployments are trying new features for credit scoring, usage and drive uptake which is currently at around 6 million users (Hwang and Tellez, 2016; Totolo, 2018). In SSA, 95 million adults who are un(der) banked receive cash payment and 65 million use semi-formal savings (IFC, 2018) with 57\% financially excluded (IFC, 2018) and banks penetration being below 35\% (IFC, 2017). Digitisation of retail payments involves challenges that must be an attractive option for the customers and the service providers (Demirguc-Kunt et al., 2017; Allen et al., 2016) and regulators need to take up the challenge of taking disruptive innovations to the next level (IFC, 2018). FinTech provides an innovative approach to delivering financial services in different markets, partly due to the perceived inability of traditional lenders (World Bank, 2019).

A better understanding of the social economic characteristics of the low income earners can be an effective antidote in designing tailor made policies on financial inclusion. The low income earners can be clustered into different groups and have higher probability of being un(der) banked but the probability varies significantly within the group (Hayashi and Minhas, 2017). There is growing consumer demand for digital financial services as innovations in the financial sector continue to advance as usage and 
access of financial services are influenced by the socioeconomic characteristics of the customers (Allen et al., 2016).

The study considers the issue of financial inclusion and analyses the socio-economic characteristics and financial literacy of the consumers and how they shape the credit usage among the un(der) banked from the financial service providers. The opportunities that have been presented by FinTech and influence consumers toward credit usage are highlighted.

The rest of the paper is organised as follows. Section 2 presents the literature review and Section 3 has the methodology. Section 4 has the results and discussions and Section 5 the concluding remarks.

\section{FinTech and socio-economic characteristics}

FinTech is the future of Africa's credit access as what now matters to the consumers is the ability to access the services they desire irrespective of the kind of the provider. The penetration of smartphones in Africa is growing, expected to be 720 million by 2020 from 226 million in 2015 (IFC, 2018). The growth of social media networks and availability of big data continue to permeate our lives (Ntwiga and Weke, 2016). Social interactions generate a trail of data, Social Media Data (SMD) that contains our abilities and dispositions. Ntwiga (2016) noted that the availability of powerful data science tools for mining SMD offers a rich set of data for consumer credit scoring. This reduces information asymmetry among the un(der) banked (Jagtiani and Lemieux, 2018). This is an opportunity for behavioural credit scoring where the consumer payment behaviour patterns are evaluated which reflects changes in the risk profile over time. When this process is automated, routine decisions can easily be made (World Bank, 2019). Big data can loop in consumers with no financial history and un(der)banked to gain better insights and reduce information asymmetry (Daniel and Grissen, 2015) and (Jagtiani and Lemieux, 2018) noted that soft information improves the credit scoring process for the FinTech to supplement the availability of unsecured consumer credit.

Financial inclusion and individual socio-economic characteristics like gender, age, income, education, marital status and household size influence on credit usage are similar to the sentiments of various research work (Totolo, 2018; Kranz, 2005; Demirguc-Kunt et al., 2017; Allen et al., 2016; Djankov et al., 2008; Ntwiga, 2017). Household attributes like wealth and education are strongly correlated with usage of formal financial sector with less educated not saving or borrowing (Djankov et al., 2008). Financial literacy and education levels influence awareness, access and usage of credit services. Employment (wealth or income) is also among the important indicators of credit usage and access as well as geographic region, urban versus rural areas (Kranz, 2005). The characteristics of the borrowers differ by gender, purpose of the loans, age and trust they have toward FinTechs (Totolo, 2018).

The social characteristics of access and usage are age, education, employment and gender of the consumer. The male and female profiles of access and usage differ with young people likely to demand less of credit, and this indicates differences based on age. Women have a higher rate of using informal financial services at $51.4 \%$ compared to men at $30.9 \%$. In the use of mobile financial services, the difference between men $(75.5 \%)$ and women $(67.5 \%)$ is $8 \%$ (FSD, 2016, 2014, 2010). The education level, age, race, marital status, ownership of mobile phone, employment status and technology use are factors that contribute to the likelihood of the low income earners being unbanked. 
Low income households with (without) internet access have significantly lower (higher) probability of being unbanked (Hayashi and Minhas, 2017).

Influences of risk perceptions are unpredictable outcomes, emotional reactions, uncertainty due to lack of knowledge and seriousness of the consequences. Agaliotis and Hadzic (2015) noted that consumer behaviour observed over different products offers differing price sensitivity reactions and Beckett et al. (2000) noted that the influence is based on the type of financial product. The subjectivity of how risk is perceived creates uncertainities due to lack of knowledge and consequences there in Diacon and Ennew (2001). A robust relationship between financial behaviour and perceptions on credit access exists (Annim et al., 2012) as trust forms the link in the relationship (Beckett et al., 2000).

\section{Research methodology}

The data source is the 2016 FinAccess Household Survey data which is both qualitative and quantitative collected collaboratively by Central Bank of Kenya, Kenya National Bureau of Statistics and Financial Sector Deepening in 2015. A total of 8665 households were interviewed on access and usage of financial services in Kenya during the period of the study. The data is rich and deep on financial usage and access, covering knowledge and understanding of our financial products and services (FSD, 2016). The analysis on this data is to understand how the socio-economic characteristics and financial literacy of the consumers influence credit usage among the financial service providers. The socioeconomic characteristics are, income, gender, marital status, age, education level and geographical cluster, and financial literacy. These are analysed with the Multinomial regression. A qualitative analysis based on desktop reviews on the influence of FinTech on consumers towards credit usage is presented. The Multinomial logistic regression model can be generalised as:

$$
\log \left(\frac{\pi_{i}^{j}}{\pi^{0}}\right)=Y_{i}=\alpha^{(j)}+\beta_{i}^{(j)} X_{1 j}++\beta_{k}^{(j)} X_{k j}
$$

where $i=1,2, \ldots, C-1$, with $C=3$ being the number of categories in the response variable. $k=1,2, \ldots, K-1$, with $K$ being the number of categories in each explanatory variable. The $C-1$ and $K-1$ means that one of the categories is the reference category in the logit regression and $j=1,2, \ldots, N$, being the number of explanatory variables in the model. $\alpha^{(j)}, \beta_{1}^{(j)}, \ldots, \beta_{k}^{(j)}$ are unknown population parameters to be estimated in the logit regression model. The observations $Y_{i}$ have a multinomial distribution with probability parameters: $\pi_{i}^{(0)}, \pi_{i}^{(1)}, \ldots, \pi_{i}^{(C-1)}$, where $i=1,2, \ldots, N$ and $C=3$. There are $X_{1}, X_{2}, \ldots, X_{K}$ explanatory variables for each of the $N$ set of observations.

Table 2 shows that the eight variables: household head, financial literacy, geographic cluster, education level, marital status, age groups and income groups, had $1<V I F<2$, thus no multicollinearity is evident among the variables. This means Multinomial logistic regression model can be used to analyse the data. The correct classification of the three categories in the response variable is tabulated in Table 1 based on the 2016 FinAccess Household Survey. 
Table 1 shows the predicted classification on the three categories of credit usage. The categories $C=3$ are: currently have credit, used to have credit and never had credit, with the later as the reference category. The model correctly classify $63.9 \%$ of the subjects in currently have credit with $7.8 \%$ of used to have credit and $57.2 \%$ of the never had credit being correctly classified. Overall, the success rate is $45.5 \%$ for the model to correctly classify the three categorical variables.

Table 1 Classification of the response variable categories

\begin{tabular}{lcccc}
\hline & \multicolumn{4}{c}{ Predicted } \\
\hline Observed & Currently have & Used to have & Never had & $\begin{array}{c}\text { Per cent } \\
\text { correct (\%) }\end{array}$ \\
\hline Currently have & $4,693,516$ & 440,455 & $2,215,715$ & 63.9 \\
Used to have & $2,881,364$ & 435,624 & $2,291,733$ & 7.8 \\
Never had & $2,464,030$ & 354,886 & $3,771,507$ & 57.2 \\
Overall percentage (\%) & 51.4 & 6.3 & 42.4 & 45.5 \\
\hline
\end{tabular}

\section{Results and discussions}

The objective is to analyse how financial literacy, socio-economic characteristics and FinTech influence credit usage from the financial service providers among the un(der) banked customers.

\subsection{Credit usage and socio-economic characteristics}

The socio-economic characteristics are age, education level, gender of the household head, income, marital status and geographic cluster. The multinomial logistic regression predicted the odds of the credit usage to the socio-economic characteristics and financial literacy among the consumers.

Table 2 shows the categories of the response variable (three categories) and explanatory variable each has between two and nine categories. The reference category is the last category for each variable. There is no multicollinearity evident among the variables $1<V I F<2$, thus Multinomial regression is a good candidate for analysis.

The plots in Figure 1 are discussed with reference to Table 2. The first plot (financial literacy) shows that customers with low literacy level have high proportions of those who never used credit but those with high financial literacy have high proportions of who are currently using or have used credit. In the second plot (age groups in years), the group of 16-30 years had the highest number of those who have never used credit, while the group 31-45 had the highest number of those currently using credit. In plot three (gender), the male and female proportions of those who currently have, used to have and never had credit is almost the same. Plot four (marital status) shows that those married or living with a partner currently have credit, while in plot five (education level), those who have completed primary or secondary education had an equal number of credit usage while tertiary educated had a high number of those currently have credit. In plot six (geographic cluster), the proportions are almost the same in credit usage and in plot seven (income levels), those earning 3000 or less had a high proportion that has never used credit while those earning between 3001 and 100,000 were high users of credit. Plot eight 
compares the financial literacy level and education level, where those with no formal schooling had the lowest financial literacy and those with tertiary level with highest proportion of those who had the highest financial literacy levels.

Table 2 Summary of credit usage and socio-economic characteristics of the consumer

\begin{tabular}{|c|c|c|c|c|}
\hline Variable & Categories & Code & Per cent & $V I F$ \\
\hline \multirow{3}{*}{ Credit usage } & Currently have credit & $\mathrm{C}-1$ & 37.6 & \\
\hline & Used to have credit & $\mathrm{C}-2$ & 28.7 & \\
\hline & Never had credit & $\mathrm{C}-3$ & 33.7 & \\
\hline \multirow{2}{*}{ Household head } & Male & G-1 & 77.5 & \multirow{2}{*}{1.181} \\
\hline & Female & $\mathrm{G}-2$ & 22.5 & \\
\hline \multirow{3}{*}{ Financial literacy } & Low & FL-1 & 27.6 & \multirow{3}{*}{1.513} \\
\hline & Medium & FL-2 & 36.9 & \\
\hline & High & FL-3 & 35.5 & \\
\hline \multirow{2}{*}{$\begin{array}{l}\text { Geographic } \\
\text { cluster: } \\
\text { Rural/Urban }\end{array}$} & Rural & GC-1 & 61.4 & \multirow[b]{2}{*}{1.149} \\
\hline & Urban & $\mathrm{GC}-2$ & 38.6 & \\
\hline \multirow{4}{*}{$\begin{array}{l}\text { Education level of } \\
\text { respondent }\end{array}$} & None & E-1 & 9.8 & \multirow{4}{*}{1.644} \\
\hline & Primary & E-2 & 46.1 & \\
\hline & Secondary & E-3 & 32.5 & \\
\hline & Tertiary & E-4 & 11.6 & \\
\hline \multirow{5}{*}{ Marital status } & Single & MS-1 & 24.5 & \multirow{5}{*}{1.324} \\
\hline & Divorced/Separated & MS-2 & 4.9 & \\
\hline & Widowed & MS-3 & 8.5 & \\
\hline & Married/Living with partner & MS-4 & 61.9 & \\
\hline & Don’t know & MS-5 & 0.2 & \\
\hline \multirow{5}{*}{$\begin{array}{l}\text { Age groups } \\
\text { (in years) }\end{array}$} & $16-30$ & AG-1 & 43.5 & \multirow{5}{*}{1.222} \\
\hline & $31-45$ & AG-2 & 31.6 & \\
\hline & $46-60$ & AG-3 & 14.5 & \\
\hline & $61-75$ & AG-4 & 7.6 & \\
\hline & $>75$ & AG-5 & 2.8 & \\
\hline \multirow{9}{*}{$\begin{array}{l}\text { Income groups } \\
\text { (KES) }\end{array}$} & $<100$ & IG-1 & 1.8 & \multirow{9}{*}{1.266} \\
\hline & $101-1500$ & IG-2 & 12 & \\
\hline & $1501-3000$ & IG-3 & 14.3 & \\
\hline & $3001-7500$ & IG-4 & 24.0 & \\
\hline & $7501-15,000$ & IG-5 & 22.3 & \\
\hline & $15,001-30,000$ & IG-6 & 15.3 & \\
\hline & $30,001-100,000$ & IG-7 & 8.8 & \\
\hline & $100,001-200,000$ & IG-8 & 0.9 & \\
\hline & $>200,000$ & IG-9 & 0.6 & \\
\hline
\end{tabular}

Notes: $\quad$ Pseudo $R$-squared, Nagelkerke $=0.111$.

VIF - Variance Inflation Factor (test for multicollinearity). 
Figure 1 Credit usage against financial literacy and socio-economic characteristics of the consumer
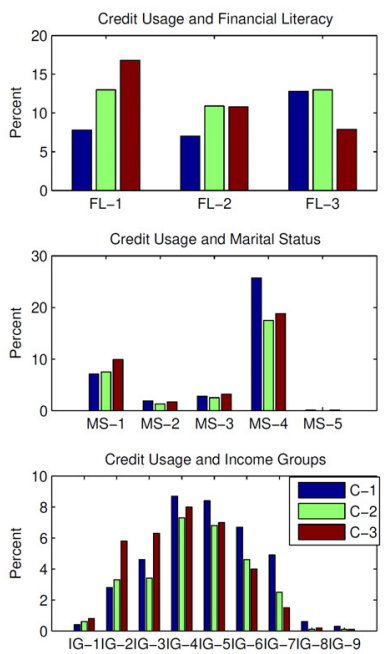
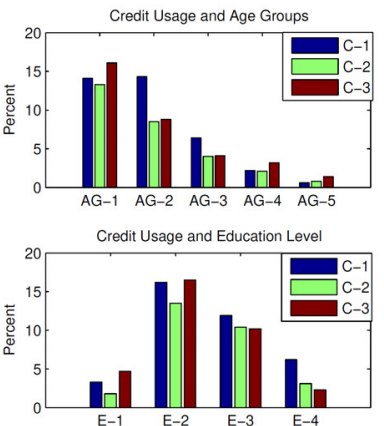

Financial Literacy

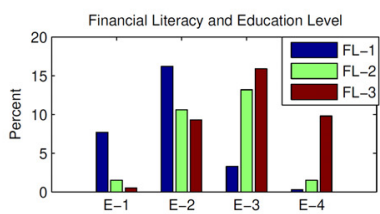

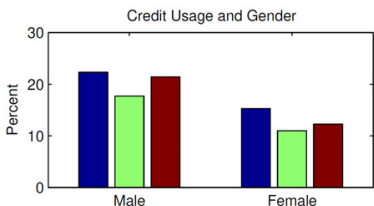

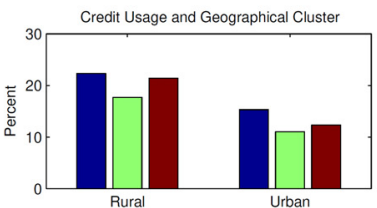

The output in Table 3 shows the parameter estimates of the multinomial logistic regression for the analysis of the financial literacy and the socio-economic characteristics of the consumer and how they affect credit usage.

Table 3 Parameter estimates for socioeconomic characteristics and financial literacy

\begin{tabular}{|c|c|c|c|c|c|c|c|c|c|}
\hline & & & & & & & & \multicolumn{2}{|c|}{95 CI for $\operatorname{Exp}(B)$} \\
\hline $\begin{array}{l}\text { Credit } \\
\text { usage }\end{array}$ & Code & $B$ & Std. error & Wald & $d f$ & Sig. & $\operatorname{Exp}(B)$ & $\begin{array}{c}\text { Low } \\
\text { bound }\end{array}$ & $\begin{array}{l}\text { Upper } \\
\text { bound }\end{array}$ \\
\hline $\mathrm{C}-1$ & Intercept & .234 & .016 & 219.692 & 1 & .000 & & & \\
\hline & G-1 & -.089 & .002 & 3105.469 & 1 & 0.000 & .915 & .912 & .917 \\
\hline & G-2 & 0 & & & 0 & & & & \\
\hline & FL-1 & -.998 & .002 & 316191.239 & 1 & 0.000 & .369 & .367 & .370 \\
\hline & FL-2 & -.557 & .001 & 141777.975 & 1 & 0.000 & .573 & .571 & .574 \\
\hline & FL-3 & 0 & & & 0 & & & & \\
\hline & GC-1 & .147 & .001 & 13931.852 & 1 & 0.000 & 1.159 & 1.156 & 1.161 \\
\hline & GC-2 & 0 & & & 0 & & & & \\
\hline & E-1 & -.402 & .003 & 17967.080 & 1 & 0.000 & .669 & .665 & .673 \\
\hline & E-2 & -.456 & .002 & 39724.801 & 1 & 0.000 & .634 & .631 & .637 \\
\hline & E-3 & -.435 & .002 & 40288.070 & 1 & 0.000 & .648 & .645 & .650 \\
\hline & E-4 & 0 & & & 0 & & & & \\
\hline & MS-1 & .037 & .013 & 8.128 & 1 & .004 & 1.038 & 1.012 & 1.065 \\
\hline & MS-2 & .584 & .013 & 1966.493 & 1 & 0.000 & 1.794 & 1.748 & 1.841 \\
\hline & MS-3 & .707 & .013 & 2898.336 & 1 & 0.000 & 2.028 & 1.976 & 2.080 \\
\hline & MS-4 & .675 & .013 & 2694.167 & 1 & 0.000 & 1.964 & 1.915 & 2.015 \\
\hline & MS-5 & 0 & & & 0 & & & & \\
\hline
\end{tabular}


Table 3 Parameter estimates for socioeconomic characteristics and financial literacy (continued)

\begin{tabular}{|c|c|c|c|c|c|c|c|c|c|}
\hline \multirow{2}{*}{$\begin{array}{l}\text { Credit } \\
\text { usage }\end{array}$} & \multirow[b]{2}{*}{ Code } & \multirow[b]{2}{*}{$B$} & \multirow[b]{2}{*}{ Std. error } & \multirow[b]{2}{*}{ Wald } & \multirow[b]{2}{*}{$d f$} & \multirow[b]{2}{*}{ Sig. } & \multirow[b]{2}{*}{$\operatorname{Exp}(B)$} & \multicolumn{2}{|c|}{95 CI for $\operatorname{Exp}(B)$} \\
\hline & & & & & & & & $\begin{array}{c}\text { Low } \\
\text { bound }\end{array}$ & $\begin{array}{l}\text { Upper } \\
\text { bound }\end{array}$ \\
\hline & AG-1 & .559 & .004 & 19932.082 & 1 & 0.000 & 1.749 & 1.736 & 1.763 \\
\hline & AG-2 & .869 & .004 & 48939.390 & 1 & 0.000 & 2.385 & 2.367 & 2.404 \\
\hline & AG-3 & .857 & .004 & 45844.293 & 1 & 0.000 & 2.357 & 2.339 & 2.376 \\
\hline & AG-4 & .276 & .004 & 4422.147 & 1 & 0.000 & 1.317 & 1.307 & 1.328 \\
\hline & AG-5 & 0 & & & 0 & & & & \\
\hline & IG-1 & -1.068 & .009 & 12992.459 & 1 & 0.000 & .344 & .337 & .350 \\
\hline & IG-2 & -.955 & .008 & 12917.490 & 1 & 0.000 & .385 & .379 & .391 \\
\hline & IG-3 & -.695 & .008 & 6940.175 & 1 & 0.000 & .499 & .491 & .507 \\
\hline & IG-4 & -.403 & .008 & 2362.194 & 1 & 0.000 & .669 & .658 & .680 \\
\hline & IG-5 & -.391 & .008 & 2236.998 & 1 & 0.000 & .676 & .665 & .687 \\
\hline & IG-6 & -.258 & .008 & 965.192 & 1 & .000 & .773 & .760 & .786 \\
\hline & IG-7 & .239 & .008 & 805.242 & 1 & .000 & 1.270 & 1.249 & 1.291 \\
\hline & IG-8 & .478 & .010 & 2075.942 & 1 & 0.000 & 1.613 & 1.580 & 1.647 \\
\hline & IG-9 & 0 & & & 0 & & & & \\
\hline $\mathrm{C}-2$ & Intercept & -.455 & .018 & 641.231 & 1 & .000 & & & \\
\hline & G-1 & .066 & .002 & 1610.997 & 1 & 0.000 & 1.069 & 1.065 & 1.072 \\
\hline & G-2 & 0 & & & 0 & & & & \\
\hline & FL-1 & -.695 & .002 & 144618.962 & 1 & 0.000 & .499 & .497 & .501 \\
\hline & FL-2 & -.407 & .002 & 69524.773 & 1 & 0.000 & .665 & .663 & .667 \\
\hline & FL-3 & 0 & & & 0 & & & & \\
\hline & GC-1 & .194 & .001 & 22441.507 & 1 & 0.000 & 1.215 & 1.212 & 1.218 \\
\hline & GC-2 & 0 & & & 0 & & & & \\
\hline & E-1 & -.756 & .003 & 50326.043 & 1 & 0.000 & .470 & .467 & .473 \\
\hline & E-2 & -.131 & .002 & 2781.136 & 1 & 0.000 & .878 & .873 & .882 \\
\hline & E-3 & -.022 & .002 & 90.609 & 1 & .000 & .978 & .973 & .982 \\
\hline & E-4 & 0 & & & 0 & & & & \\
\hline & MS-1 & .346 & .015 & 545.163 & 1 & .000 & 1.414 & 1.373 & 1.456 \\
\hline & MS-2 & .542 & .015 & 1304.283 & 1 & .000 & 1.719 & 1.669 & 1.770 \\
\hline & MS-3 & .930 & .015 & 3886.350 & 1 & 0.000 & 2.535 & 2.462 & 2.610 \\
\hline & MS-4 & .634 & .015 & 1833.366 & 1 & 0.000 & 1.885 & 1.831 & 1.941 \\
\hline & MS-5 & 0 & & & 0 & & & & \\
\hline & AG-1 & .012 & .004 & 10.110 & 1 & .001 & 1.012 & 1.005 & 1.019 \\
\hline & AG-2 & -.001 & .004 & .031 & 1 & .861 & .999 & .992 & 1.007 \\
\hline & AG-3 & .059 & .004 & 242.298 & 1 & .000 & 1.061 & 1.053 & 1.069 \\
\hline & AG-4 & -.139 & .004 & 1289.611 & 1 & .000 & .870 & .863 & .876 \\
\hline
\end{tabular}


Table 3 Parameter estimates for socioeconomic characteristics and financial literacy (continued)

\begin{tabular}{cccccccccc}
\hline & & & & & & \multicolumn{5}{c}{ 95 CIfor Exp(B) } \\
\hline $\begin{array}{c}\text { Credit } \\
\text { usage }\end{array}$ & Code & $B$ & Std. error & Wald & $d f$ & Sig. & Exp(B) & $\begin{array}{c}\text { Low } \\
\text { bound }\end{array}$ & $\begin{array}{c}\text { Upper } \\
\text { bound }\end{array}$ \\
\hline & AG-5 & 0 & & & 0 & & & & \\
& IG-1 & -.011 & .010 & 1.042 & 1 & .307 & .989 & .969 & 1.010 \\
& IG-2 & -.191 & .010 & 383.850 & 1 & .000 & .826 & .810 & .842 \\
& IG-3 & -.307 & .010 & 991.973 & 1 & .000 & .736 & .722 & .750 \\
& IG-4 & .158 & .010 & 264.819 & 1 & .000 & 1.171 & 1.149 & 1.193 \\
& IG-5 & .161 & .010 & 278.711 & 1 & .000 & 1.175 & 1.153 & 1.198 \\
& IG-6 & .209 & .010 & 463.179 & 1 & .000 & 1.232 & 1.209 & 1.256 \\
& IG-7 & .489 & .010 & 2475.556 & 1 & 0.000 & 1.631 & 1.600 & 1.663 \\
& IG-8 & -.219 & .013 & 286.252 & 1 & .000 & .804 & .784 & .824 \\
IG-9 & 0 & & & 0 & & & & \\
\hline
\end{tabular}

Note: The reference category is: Never had credit or code C-3 (see Table 2)

\subsubsection{Currently have credit relative to never had credit}

This is the multinomial logit estimate for currently have credit relative to never had credit for the socio-economic characteristics and financial literacy.

Gender

For males as household head relative to females, the relative risk for currently have credit to never had credit would be expected to decrease by a factor of 0.915 given the other variables in the model are held constant (logit for males relative to females is -0.089 ). That is, males are less likely than female household heads to currently have credit relative to never had credit. Since $(p<0.001)$, the difference between males and female household heads has been found to be statistically different for currently have to never had credit given the other socio-economic characteristics in the model. Therefore, female households are more likely to currently have credit as compared to their male counterparts.

\section{Financial literacy}

Consumers with low and medium financial literacy relative to high financial literacy, the relative risk for currently have credit to never had credit would be expected to decrease by a factor of 0.369 and 0.573 , respectively given the other variables in the model are held constant (logit for low and medium financial literacy relative to high financial literacy is -0.998 and -0.557 , respectively). That is, consumers with low and medium financial literacy are less likely than those with high financial literacy to currently have credit relative to never had credit. Since $(p<0.001)$, the difference between low, medium and high financial literacy has been found to be statistically different for currently have to never had credit given the other socio-economic characteristics in the model. Credit usage increases with the level of financial literacy. 


\section{Geographic cluster}

For rural dwellers relative to urban dwellers, the relative risk for currently have credit to never had credit would be expected to increase by a factor of 1.159 given the other socio-economic characteristics in the model are held constant(logit for rural relative to urban dwellers is 0.147 ). That is, rural dwellers are more likely than urban dwellers to currently have credit relative to never had credit. Since $(p<0.001)$, the difference between rural and urban dwellers has been found to be statistically different for currently have to never had credit given the other socio-economic characteristics in the model. Therefore, rural dwellers are more likely to currently have credit as compared to their urban counterparts.

\section{Education}

Consumers with non-education, primary and secondary education level relative to tertiary education level, the relative risk for currently have credit to never had credit would be expected to decrease by a factor of $0.669,0.634$ and 0.648 , respectively given the other socio-economic characteristics in the model are held constant (logit for none, primary and secondary education level relative to tertiary education is $-0.402,-0.456$ and -0.435 , respectively). That is, consumers with no education, primary and secondary education are less likely than those with tertiary education to currently have credit relative to never had credit. Since $(p<0.001)$, the difference between none, primary, secondary and tertiary education has been found to be statistically different for currently have to never had credit given the other socio-economic characteristics in the model. An increase in education level increases the current usage of credit.

\section{Marital status}

The single, divorced/separated, widowed and married/living with a partner relative to those who did not disclose their marital status (stated don't know), the relative risk for currently have credit to never had credit would be expected to increase by a factor of $1.038,1.794,2.028$ and 1.964, respectively given the other socio-economic characteristics in the model are held constant(logit for single, divorced/separated, widowed and married/living together relative to don't know their marital status is $0.037,0.584,0.707$ and 0.675 , respectively). That is, consumers who are single, divorced/separated, widowed and married/living together are more likely to currently have credit relative to never had credit. Since $(p<0.001)$, the difference between being single, divorced/separated, widowed, married/living together and no known marital status has been found to be statistically different for currently have to never had credit given the other socio-economic characteristics in the model. Those consumers who know their marital status as compared to those who did not know are more likely to have credit at the moment. Therefore, self-identity in terms of marital status is crucial in propelling a consumer to credit usage.

\section{Age}

The age categories, $16-30,31-45,46-60$ and $61-75$ relative to those aged $>75$, the relative risk for currently have credit to never had credit would be expected to increase by a factor of $1.749,2.385,2.357$ and 1.317 , respectively given the other socio-economic characteristics in the model are held constant (logit for age group 16-30, 31-45, 46-60 
and $61-75$ relative to the age group of $>75$ is $0.559,0.869,0.857$ and 0.276 , respectively). That is, those in the age of 16 years to 75 years are more likely to currently have credit relative to never had credit compared to those age over 75 years. Since $(p<0.001)$, the difference between being in the age groups 16-30, 31-45, 46-60, $61-75$ and $>75$ has been found to be statistically different for currently have to never had credit given the other socio-economic characteristics in the model. Credit usage is highest for the age groups $31-45,46-60,16-30$ and $61-75$ in that order.

Income

The income groupings, <100,101-1500,1501-3000,3001-7500, 7501-15,000, $15,001-30,000,30,001-100,000$ and 100,001-200,000 relative to those aged $>200,000$, the relative risk for currently have credit to never had credit would be expected to increase by a factor of $0.344,0.385,0.499,0.669,0.676,0.773,1.270$ and 1.613 , respectively given the other socio-economic characteristics in the model are held constant (logit for income groupings <100,101-1500,1501-3000,3001-7500, $7501-15,000,15,001-30,000,30,001-100,000$ and $100,001-200,000$ relative to the income group $>200,000$ is $-1.068,-0.955,-0.695,-0.403,-0.391,-0.258,0.239$ and 0.478 , respectively). That is, those in the income group of between 100 and 30,000 are less likely to currently have credit relative to never had credit compared to those with income above 200,000. For the income of between 30,001 and 200,000, they are more likely to currently have credit relative to never had credit compared to those with an income above 200,000. An increase in income increased the chances of currently having credit compared to never had credit.

\subsubsection{Used to have credit relative to never had credit}

This is the multinomial logit estimate for used to have credit relative to never had credit for the socio-economic characteristics and financial literacy.

Gender

For males as household head relative to females, the relative risk for used to have credit to never had credit would be expected to increase by a factor of 1.069 given the other variables in the model are held constant (logit for males relative to females is 0.066). That is, males are more likely than female household heads to have had credit relative to never had credit. Since $(p<0.001)$, the difference between males and female household heads has been found to be statistically different for used to have to never had credit given the other socio-economic characteristics in the model. Therefore, male households are more likely to have had credit in the past as compared to their female counterparts.

\section{Financial literacy}

Consumers with low and medium financial literacy relative to high financial literacy, the relative risk for used to have credit to never had credit would be expected to decrease by a factor of 0.499 and 0.665 , respectively given the other variables in the model are held constant(logit for low and medium financial literacy relative to high financial literacy is -0.695 and -0.407 , respectively). That is, consumers with low and medium financial literacy are less likely than those with high financial literacy to have had credit relative to 
never had credit. Since $(p<0.001)$, the difference between low, medium and high financial literacy has been found to be statistically different for used to have to never had credit given the other socio-economic characteristics in the model. The past credit usage increases with increasing financial literacy level.

\section{Geographic cluster}

For rural dwellers relative to urban dwellers, the relative risk for used to have credit to never had credit would be expected to increase by a factor of 1.215 given the other socioeconomic characteristics in the model are held constant (logit for rural relative to urban dwellers is 0.194). That is, rural dwellers are more likely than urban dwellers to have had credit relative to never had credit. Since $(p<0.001)$, the difference between rural and urban dwellers has been found to be statistically different for used to have to never had credit given the other socio-economic characteristics in the model. Therefore, rural dwellers are more likely to have had credit as compared to their urban counterparts.

\section{Education}

Consumers with non-education, primary and secondary education level relative to tertiary education level, the relative risk for used to have credit to never had credit would be expected to decrease by a factor of $0.470,0.878$ and 0.978 , respectively given the other socio-economic characteristics in the model are held constant (logit for none, primary and secondary education level relative to tertiary education is $-0.756-0.131$ and -0.022 , respectively). That is, consumers with no education, primary and secondary education are less likely than those with tertiary education to have had credit relative to never had credit. Since $(p<0.001)$, the difference between none, primary, secondary and tertiary education has been found to be statistically different for used to have had credit to never had credit given the other socio-economic characteristics in the model. An increase in education level increased the past usage of credit.

\section{Marital status}

The single, divorced/separated, widowed and married/living with a partner relative to those who did not disclose their marital status (stated don't know), the relative risk for used to have credit to never had credit would be expected to increase by a factor of $1.414,1.719,2.535$ and 1.885, respectively given the other socio-economic characteristics in the model are held constant (logit for single, divorced/separated, widowed and married/living together relative to don't know their marital status is $0.346,0.542,0.930$ and 0.634 , respectively). That is, consumers who are single, divorced/separated, widowed and married/living together are more likely to have had credit relative to never had credit. Since $(p<0.001)$, the difference between being single, divorced/separated, widowed, married/living together and no known marital status has been found to be statistically different for used to have had credit given the other socio-economic characteristics in the model. Those consumers who know their marital status as compared to those who did not know are more likely to have credit at the moment, with the widowed having the highest chance to have ever had credit in this category. 
Age

The age categories, $16-30,31-45,46-60$ and $61-75$ relative to those aged $>75$, the relative risk for used to have credit to never had credit would be expected to increase by a factor of $1.749,2.385,2.357$ and 1.317 , respectively given the other socioeconomic characteristics in the model are held constant (logit for age group $16-30,31-45,46-60$ and $61-75$ relative to the age group of $>75$ is $1.012,0.999,1.061$ and 0.870 , respectively). That is, those in the age of 16 years to 75 years are more likely to have had credit relative to never had credit compared to those age over 75 years. Since $(p<0.001)$, the difference between being in the age groups $16-30,46-60,61-75$ and $>75$ has been found to be statistically different for used to have to never had credit given the other socio-economic characteristics in the model. The findings for the age group 31-45 is not statistically significant for the past credit usage. Therefore, the past credit usage increased for the age groups 16-30 and 46-60.

Income

The income groupings, $<100,101-1500,1501-3000,3001-7500,7501-15,000$, $15,001-30,000,30,001-100,000$ and $100,001-200,000$ relative to those aged $>200,000$, the relative risk for used to have credit to never had credit would be expected to increase by a factor of $0.989,0.826,0.736,1.171,1.175,1.232,1.631$ and 0.804 , respectively given the other socio-economic characteristics in the model are held constant (logit for income groupings $<100,101-1500,1501-3000,3001-7500,7501-$ $15,000,15,001-30,000,30,001-100,000$ and $100,001-200,000$ relative to the income group $>200,000$ is $-0.011,-0.191,-0.307,0.158,0.161,0.209,0.489$ and 0.219 , respectively). That is, those in the income group of between 100 and 3000 and for the income group 100,001-200,000 are less likely to have had credit relative to never had credit compared to those with income above 200,000. For the income of between 3001 and 100,000 , they are more likely to have had credit relative to never had credit compared to those with an income above 200,000. An income of 3001 and above increased the chances of having had credit in the past.

\subsection{FinTech influence on consumers}

The opportunities availed by FinTech to the consumers are highlighted in this section based on a desktop research. These factors can increase credit usage among the un(der) banked (IFC, 2018; Demirguc-Kunt et al., 2017; Jagtiani and Lemieux, 2017; Hwang and Tellez, 2016; Ivatury and Pickens, 2006; Jagtiani and Lemieux, 2018; PWC, 2020).

FinTech continuous disruptions and innovations means an increased customer experience through services and products.

- Products and services are tailored to meet the consumer perceptions and behaviour as innovations can capture the changing trends and shifting demographics using big data and artificial intelligence.

- Consumers are able to access instant loans as technology is used to register, score, allocate and disburse funds. This makes it attractive due to availability in short notices (emergencies). 
- Loan eligibility is assessed from the existing digital access of the consumer, thus not discriminated due to lack of financial histories.

- As competition and innovations shift, consumers can be offered debt restructuring through an automated flexible payment mode.

- Customers can make choices of alternative financial services online by comparison and this increases the expectations as shaped by experiences outside of the banking hall.

- Customers can source for financial advice from independent influences, peer conversations and "word of mouth" through use of technology.

- A new range of choices as technological features are richer with more engaging and rewarding experience for the consumer.

- High mobile penetration and technological evolution reduces barriers to entry of new customers.

- Customer relations, disbursement, repayments, and collections are managed remotely, which reduces operational costs.

- Improve the design of the purchase process to increase consumer attention to the terms and conditions.

- Generation Y has a high propensity to use mobile channels and they expect a rich digital experience that integrates their banking needs and their digital lives.

- Clustering consumers in different credit risk profiles due to increase in the availability of big data and technological advancements.

- Build the trust and confidence of the consumers by investing in customer care services and offer customised reward programs to increase customer retention and experience.

- Innovative use of big data and Artificial Intelligence (AI) for marketing, risk management based on the customer's risk profile and to model the changing trends and shifting demographics of the consumers.

- FinTech perceived risk, technological risk and failure and lack a regulatory framework to protect the consumer can erode the gains made in the sector.

\section{Conclusions}

The logit for currently have credit relative to never had credit is influenced by gender as female household heads are more likely to have credit at the moment as compared to the male counterparts. Those living in rural areas are higher partakers of credit as compared to urban dwellers. For the financial literacy, an increase in financial literacy increases current credit usage. An increase in education level and income increases current credit usage. In the marital status category, self-identity is crucial for current usage of credit as compared to those not sure of their marital status. Age had a positive influence on 
current credit usage but the uptake is non-linear. The socio-economic characteristics and financial literacy have an influence on current credit usage relative to never having had credit.

The logit for used to have credit relative to never had credit is influenced by gender where male household heads were more likely to have used credit as compared to the female household heads. The rural dwellers had higher chances than urban dwellers to have had credit with increase in financial literacy increasing past usage of credit. An increase in education level increased past credit usage with the widowed having a higher past history of credit usage. An increase in income increases past usage of credit. Therefore, the past usage of credit relative to never having used credit is influenced by the financial literacy and the socio-economic characteristics of the consumer.

There exists varied and diverse opportunities for the FinTech to influence consumers on how they access and use credit. Key contributions being customised products and services to the consumers, use of big data to cluster customers into different risk profiles, ease of use and availability during emergencies. The service providers are able to reduce operating costs, better understand and offer more rewarding experience to their clients using FinTech.

Recommendation for further research is to analyse the relationship between credit usage and credit access from the 2016 FinAccess Household survey data as this data set is rich and deep on financial usage and access, covering knowledge, perceptions, behaviour and understanding of financial services and products.

\section{References}

Agaliotis, K. and Hadzic, M. (2015) 'Predicting retail banking consumer behaviour using statistics', The European Journal of Applied Economics, Vol. 12, No. 1, pp.43-51. Doi: 10.5937/EJAE12-7916.

Allen, F., Demirguc-Kunt, A., Klapper, L. and Peria, M. (2016) 'The foundations of financial inclusion: understanding ownership and use of formal accounts', Journal of Financial Intermediation, Vol. 27, pp.1-30.

Amidzic, G., Massara, A. and Miolou, A. (2014) Assessing Countries' Financial Inclusion Standing - A New Composite Index, International Monetary Fund, Working Paper WP/14/36.

Annim, S., Arun, T. and Koslov, P. (2012) Effect of Perceptions and Behaviour on Access to and Use of Financial Service: Evidence from South Africa, IZA Discussion paper No. 7042.

Beckett, A., Hewer, P. and Howcroft, B. (2000) 'An exposition of consumer behaviour in the financial services industry', International Journal of Bank Marketing, MCB University Press, Vol. 18, No. 1, pp.15-26.

Daniel, B. and Grissen, D. (2015) Behavior Revealed in Mobile Phone Usage Predict Loan Repayment, Department of Economics, Brown University, Working Paper.

Demirguc-Kunt, A., Klapper, L., Singer, D. and Oudheusden, P. (2015) The Global Findex Database 2014: Measuring Financial Inclusion Around the World, Development Research Group Finance and Private Sector Development Team. Policy Research Working Paper No. 7255, The World Bank.

Demirguc-Kunt, A., Klapper, L., Singer, D., Ansar, S. and Hess, J. (2017) The Global Findex Database: Measuring Financial Inclusion and the Fintech Revolution, International Bank for Reconstruction and Development/The World Bank. 
Diacon, S. and Ennew, C. (2001) Consumer perceptions of financial risk', The Geneva Papers on Risk and Insurance, Vol. 26, No. 3, pp.389-409.

Djankov, S., Miranda, P., Seria, E. and Sharma, S. (2008) Who Are the Unbanked? Policy Research Working Paper No. 4647, World Bank.

Financial Sector Deepening (FSD) (2010) Financial Capability and the Poor: Are We Missing the Mark? Bankable Frontier Associates, Issue 2, Nairobi, Kenya.

Financial Sector Deepening (FSD) (2014) A Buck Short: What Financial Diaries Tell us about Building Financial Services that Matter to Low Income Women, Report by Bankable Frontier Associates, Nairobi, Kenya.

Financial Sector Deepening (FSD) (2016) FinAccess Household Survey: Collaboration between Financial Sector Deepening, Kenya National Bureau of Statistics and Central Bank of Kenya Report, Nairobi.

Hayashi, F. and Minhas, S. (2017) Who are the Unbanked? Characteristics Beyond Income, Federal Reserve Bank of Kansas City. Available online at: https://www.kansascityfed.org/ publications/research/articles/2018 (accessed on 4 May 2019).

Hwang, B. and Tellez, C. (2016) The Proliferation of Digital Credit Deployments, Consultative Group to Assist the Poor (CGAP) Brief March 2016.

International Finance Corporation (IFC) (2017) How Fintech is Reaching the Poor in Africa and Asia: A Start-Up Perspective, International Finance Corporation. World Bank Group. Note 34, March 2017.

International Finance Corporation (IFC) (2018) Digital Access: The future of financial inclusion in Africa. International Finance Corporation, World Bank Group.

Ivatury, G. and Pickens, M. (2006) Mobile Phone Banking and Low Income Customers: Evidence from South Africa, Consultative group to assist the poor. World Bank, Washington

Jagtiani, J. and Lemieux, C. (2017) Fintech Lending: Financial Inclusion, Risk Pricing and Alternative Information, Research Department, Federal Reserve Bank of Philadelphia, Working Paper 17-17.

Jagtiani, J. and Lemieux, C. (2018) Do Fintech Lenders Penetrate Areas that are Undeserved by Traditional Banks? Research Department, Federal Reserve Bank of Philadelphia, Working Paper 18-13.

Kranz, N.C. (2005) Indicators of Financial Access: Household Level Survey. The World Bank, Financial Sector Vice-Presidency, Conference on Measuring Access Held in Washington DC, October 2004. Available online at: http://we.worldbank.org (accessed on 21 June 2019).

McWaters, R.J. (2015) The Future of Financial Services: How Disruptive Innovations are Reshaping the Way Financial Services are Structured, Provisioned and Consumed, An industry project of the financial services community report, The World Economic Forum in collaboration with Deloitte.

Mecagni, M., Marchettini, D. and Maino, R. (2015) Evolving Banking Trends in Sub-Saharan Africa: Key Features and Challenges, African Department, International Monetary Fund.

Ntwiga, D.B. (2016) Social Network Analysis for Credit Risk Modelling, Unpublished PhD Thesis, School of Mathematics, University of Nairobi, Nairobi.

Ntwiga, D.B. (2017) 'Credit risk analysis for low income earners', Proceedings of the 6th Annual Kenya Bankers Association Banking Research Conference, September 2017, Nairobi.

Ntwiga, D.B. and Weke, P. (2016) 'Consumer lending using social media data', Journal of Scientific Research and Innovative Technology, Vol. 3, No. 2, pp.1-8.

Ntwiga, D.B., Ogutu, C. and Kirumbu, M.K. (2018) 'Inclusion of peer group and individual lowincome earners in M-shwari micro-credit lending: a hidden Markov model approach', International Journal of Electronic Finance, Vol. 9, No. 2, pp.121-133. 
PriceWaterHouseCooper (PWC) (2020) Financial Services Technology 2020 and Bbeyond: Embracing Disruption.

Totolo, E. (2018) The Digital Credit Regulation in Kenya: an Assessment of Market Demand, 5 Years on Financial Deepening Sector, Nairobi.

World Bank Group (2019) Credit Reporting Knowledge Guide 2019, The World Bank Group. 